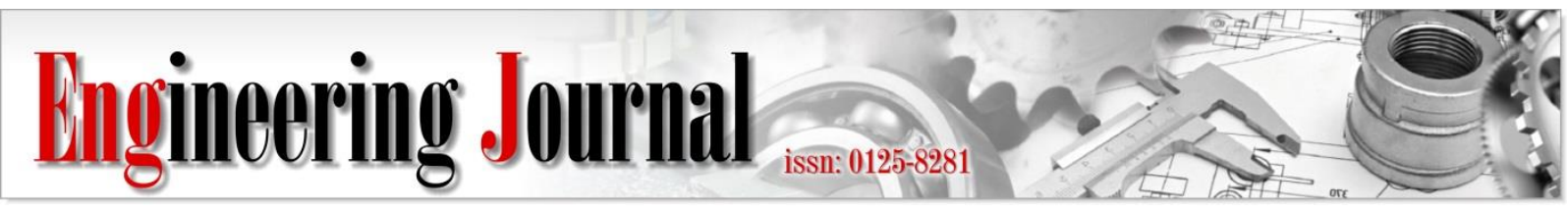

Article

\title{
Time-Dependent Model for Evaluating Corrosion Potential and Electrical Resistivity of Reinforced Concrete
}

\author{
Dong Viet Phuong Tran \\ Department of Civil Engineering, Industrial University of Ho Chi Minh City, Ho Chi Minh City, Viet Nam \\ E-mail: tranvietphuongdong@iuh.edu.vn (Corresponding author)
}

\begin{abstract}
The main work presented in this paper is to propose prediction models for estimating electrical resistivity of concrete and corrosion potential of steel in reinforced concrete. The prediction models for electrical resistivity of concrete $(r)$ and corrosion potential of steel $\left(\mathrm{E}_{\text {corr }}\right)$ incorporated hydration degree $\left(\alpha_{H y d}(t)\right)$, pozzolanic reaction degree $\left(\alpha_{P o z}(t)\right)$, porosity $\left(P_{C a p}(t)\right)$ and chloride content ([CL-]). Predicted results were verified with results of experimental measurement. An experimental program was run for 1 year with various concrete mix proportions. According to the results, corrosion resistance of concrete increased with time as the degree of hydration increased. Further, the introduction of fly ash offered a good corrosion resistance, which also increased with time. Lastly, the existence of chloride ions in the concrete weakened passive film on steel surface, by the fact that its presence eased the movement of ions in the concrete and increased the risk of corrosion.
\end{abstract}

Keywords: Steel corrosion, electrical resistivity, corrosion potential, prediction model, nondestructive test, fly ash.

ENGINEERING JOURNAL Volume 25 Issue 1

Received 3 April 2020

Accepted 29 December 2020

Published 31 January 2021

Online at http://www.engj.org/

DOI:10.4186/ej.2021.25.1.125 


\section{Introduction}

Reinforcement corrosion is a major durability problem of reinforced concrete (RC) structures. This phenomenon is caused by either carbonation or chloride attack with the latter being more serious for reinforcement corrosion [1-3]. For the structures located in marine environment, their corrosion resistance needs to be considered. Generally, there are several factors that can impact the severity of reinforcement corrosion, such as cement type, type and dosage of supplementary cementitious materials, chloride content, exposure period and so on. The corrosion resistance is usually estimated based on electrical resistivity or corrosion potential. By the fact that those mentioned parameters can represent for either restrain movement of electrons in concrete or chance of corrosion on steel surface.

Recently, prediction models, such as corrosion potential and corrosion rate, have been applied to estimate corrosion severity of reinforcement. Previous studies have shown some prediction models as well as their effectiveness on predicting the corrosion severity [4-12]. However, the effects of exposure period have yet been considered in the prediction models. Additionally, other influencing factors, such as ratio of water to binder, supplementary cementitious materials, environmental condition, etc., could be varied, especially some with the time. As a result, those aspects lead to a high variation of the predicted results.

As a cementitious material, microstructures of concrete change during the hydration process, which is time-dependent. During the process, solid phases of hydrated cement are formed as well as pore structure. Similar to other porous materials, the pore structure is a major parameter for the durability of concrete, besides other properties such as strength, shrinkage, etc. More importantly, porosity of concrete controls the movement of ions in the cementitious system [13-15]. Therefore, it affects the movement of electrons in corrosion process. Since electrical resistivity of concrete and corrosion potential of reinforcing steel are usually used to evaluate the severity of corrosion. Because of that the hydration process could impact the measured results of these two measurements.

This paper proposes two prediction models for the electrical resistivity and corrosion potential based on mix proportion of concrete and properties of cementitious materials. The time-dependent aspect was taken into account in the proposed models. Eventually, the verification of the proposed models was made by comparing the predicted results with the experimental results obtained from this study and other researchers [5, $6,16-23]$.

\section{Significance of Research}

It is necessary to have prediction models for estimating severity of corrosion. Especially the model that can consider the effect of time-dependence along with other aspects, such as concrete mix proportion, chloride concentration, etc. Although some previous models have shown their efficiencies, none has considered the effect of hydration process on the corrosion rate of reinforcement. The proposed models presented in this paper incorporated the time-dependent effects of hydration of cementitious material and chloride attack on the evaluation of reinforcement corrosion.

\section{Experimental Program}

\subsection{Materials and Specimen Preparation}

There were two types of binder system used in this study. The first system was pure OPC, where only ordinary Portland cement type I [24] was used as the binder. Meanwhile, the second was cement-fly ash cementitious system, where the OPC was mixed with fly ash type $2 \mathrm{~b}$ [25]. The chemical compositions and physical properties of the cement and fly ash are shown in Table 1. Totally 12 different concrete mix proportions were prepared for the tests in this study, as shown in Table 2. The varied parameters included water to binder ratio $(\mathrm{W} / \mathrm{B})$, replacement percentage of fly ash (FA) and chloride content ([CL-]).

The test specimens were separated into two groups. Reinforced concrete specimens $(10 \times 10 \times 10 \mathrm{~cm})$ were measured for half-cell potential, while plain concrete specimens $(15 \times 15 \times 15 \mathrm{~cm})$ were measured for electrical resistivity. After 28 days of curing, the specimens were placed in a controlled condition throughout the test periods. Inside the controlled condition, high relative humidity, RH $\geq 90 \%$, was ensured and the temperature was approximately $30^{\circ} \mathrm{C}$. More details of the experimental program can be found elsewhere $[23,26]$.

Table 1. Chemical composition and physical properties of cement and fly ash.

\begin{tabular}{|c|c|c|c|c|c|c|c|c|c|c|}
\hline $\begin{array}{c}\text { Chemical } \\
\text { composition (\%) }\end{array}$ & $\mathrm{SiO}_{2}$ & $\mathrm{Al}_{2} \mathrm{O}_{3}$ & $\mathrm{Fe}_{2} \mathrm{O}_{3}$ & $\mathrm{CaO}$ & $\mathrm{MgO}$ & $\mathrm{SO}_{3}$ & $\mathrm{Na}_{2} \mathrm{O}$ & $\mathrm{K}_{2} \mathrm{O}$ & $\begin{array}{l}\text { Free } \\
\text { lime }\end{array}$ & LOI \\
\hline Cement & 19.7 & 5.19 & 3.34 & 64.8 & 1.2 & 2.54 & 0.16 & 0.44 & 0.87 & 2.1 \\
\hline Fly ash & 25.22 & 13.88 & 17.39 & 26.25 & 2.38 & 9.44 & 1.4 & 1.92 & 3.06 & 0.56 \\
\hline $\begin{array}{l}\text { Physical } \\
\text { properties }\end{array}$ & \multicolumn{5}{|c|}{$\begin{array}{l}\text { Blaine fineness } \\
\left(\mathrm{cm}^{2} / \mathrm{g}\right)\end{array}$} & \multicolumn{5}{|c|}{ Specific gravity } \\
\hline Cement & \multicolumn{5}{|c|}{3350} & \multicolumn{5}{|c|}{3.15} \\
\hline Fly ash & \multicolumn{5}{|c|}{2722} & \multicolumn{5}{|c|}{2.54} \\
\hline
\end{tabular}


Table 2. Summary of concrete mix proportions varied in this study.

\begin{tabular}{|c|c|c|c|c|c|c|}
\hline \multirow{2}{*}{ No. } & \multirow{2}{*}{ Designation } & \multicolumn{2}{|c|}{ Materials } & \multirow{2}{*}{ W/B } & \multirow{2}{*}{$\begin{array}{c}\text { FA } \\
\%\end{array}$} & \multirow{2}{*}{$\begin{array}{c}{\left[\mathrm{CL}^{-}\right]} \\
\mathrm{kg} / \mathrm{m}^{3}\end{array}$} \\
\hline & & Cement & Fly ash & & & \\
\hline 1 & 4OPCCL0 & Type I & - & 0.4 & 0 & 0 \\
\hline 2 & 4OPCCL2 & Type I & - & 0.4 & 0 & 2 \\
\hline 3 & 4OPCCL6 & Type I & - & 0.4 & 0 & 6 \\
\hline 4 & 4FA30CL0 & Type I & Type 2b & 0.4 & 30 & 0 \\
\hline 5 & 4FA30CL2 & Type I & Type 2b & 0.4 & 30 & 2 \\
\hline 6 & 4FA30CL6 & Type I & Type 2b & 0.4 & 30 & 6 \\
\hline 7 & 6OPCCL0 & Type I & - & 0.6 & 0 & 0 \\
\hline 8 & 6OPCCL2 & Type I & - & 0.6 & 0 & 2 \\
\hline 9 & 6OPCCL6 & Type I & - & 0.6 & 0 & 6 \\
\hline 10 & 6FA30CL0 & Type I & Type 2b & 0.6 & 30 & 0 \\
\hline 11 & 6FA30CL2 & Type I & Type 2b & 0.6 & 30 & 2 \\
\hline 12 & 6FA30CL6 & Type I & Type 2b & 0.6 & 30 & 6 \\
\hline
\end{tabular}

\subsection{Nondestructive Measurements}

There were two nondestructive tests conducted in the study with their setup being illustrated in Fig. 1. A fourprobe method was applied to the plain concrete specimens $(15 \times 15 \times 15 \mathrm{~cm})$ for determining electrical resistivity of the concrete specimens. As shown in Fig. 1, Wenner fourprobe $38 \mathrm{~mm}$ type was used in this measurement with the distance between the probes being $38 \mathrm{~mm}$. Meanwhile, for the corrosion potential of reinforcing steel, a half-cell potential test was applied on the reinforced concrete specimens $(10 \times 10 \times 10 \mathrm{~cm})$ with $\mathrm{Cu} / \mathrm{CuSO}_{4}$ electrode as a reference electrode. The model of voltmeter, used in this measurement, being digital multimeter PC510. The setup of the tests as well as the evaluation of measured data were carried out based on previous suggestions [1-3, 27-29]. More details can be found elsewhere $[23,26]$.

\section{Developed Time-Dependent Models}

In this study, there are two proposed models, i.e. electrical resistivity of concrete and corrosion potential of reinforcing steel, as expressed in Eq. (1). The data of electrical resistivity and corrosion potential are obtained in this study by directly measuring on the prepared specimen. These data were then considered their correlation with the effect of time-dependent developments of concrete as well as the effect of chloride ions in concrete. The timedependent developments of concrete are represented by the degree of hydration, pozzolanic reaction and capillary porosity of fly ash-cement cementitious system, which can be determined based on the adopted models, as summarized in Table 2. More details of the adopted models are shown in section 4.1 and 4.2. The models, presented in the paper, also take the effects of chloride ions on the corrosion resistance of concrete into account. These effects are represented by the parameter $\beta_{C L}$, as expressed in Eq. (1). The regression analyses were then proceeded to establish the prediction models of electrical resistivity of concrete and corrosion potential of reinforcing steel. Lastly, the model verification was conducted by calculating the determination coefficient (Rsquared) between the analysed results and the measured data.

$$
\left\{\begin{array}{c}
r \\
E_{c o r r}
\end{array}\right\}=f\left[\alpha_{H y d}(t), \alpha_{P o z}(t), P_{C a p}(t), \beta_{C L}\right]
$$
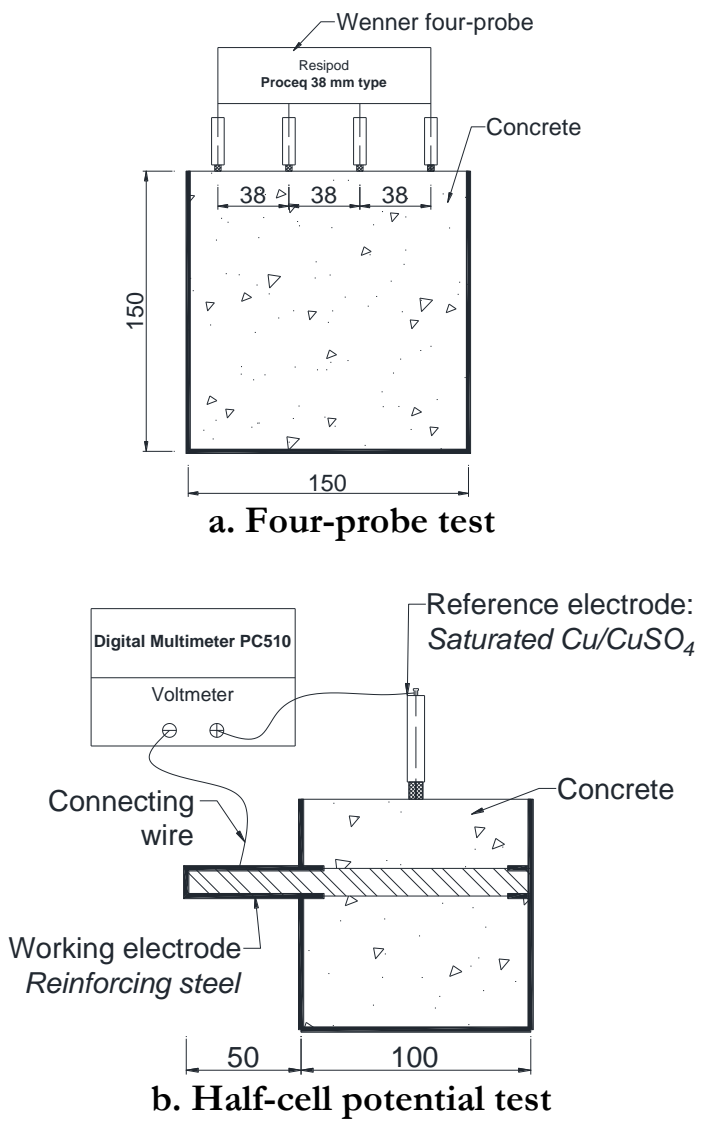

Fig. 1. Setup of two experimental tests (unit: $\mathrm{mm}$ ). 
where $\mathrm{r}$ is the electrical resistivity of concrete $(\mathrm{k} \Omega . \mathrm{cm})$, $\mathrm{E}_{\text {corr }}$ is the corrosion potential of reinforcing steel ( $\mathrm{V}$ vs. CSE), $\alpha_{H y d}(t)$ is hydration degree of cement (\%), $\alpha_{P o z}(t)$ is pozzolanic reaction degree of fly ash (\%), $P_{C a p}(t)$ is capillary porosity (\%), $\beta_{C L}$ is existing chloride ions in concrete $\left(\mathrm{kg} / \mathrm{m}^{3}\right)$.

\subsection{Degree of Reaction of Cement and Fly Ash}

\subsubsection{Degree of hydration of cement}

Degree of hydration is a ratio of hydrated cement to total cement in a mixture, as expressed in Eq. (2). This is average degree of hydration of four major oxide compounds in cement, i.e. $\mathrm{C}_{3} \mathrm{~S}, \mathrm{~S}_{2} \mathrm{~S}, \mathrm{C}_{3} \mathrm{~A}, \mathrm{C}_{4} \mathrm{AF}$. The mass of these component can be computed based on the Bogue's equation, which is based on chemical properties of the cement.

$$
\alpha_{H y d}(t)=\frac{\sum_{i=1}^{4} m_{i} \alpha_{i}(t)}{\sum_{i=1}^{4} m_{i}}
$$

where $i$ is the oxide compound $i^{\text {th }}$ of the cement; $m_{i}$ is weight of the oxide compound $\mathrm{i}^{\text {th }}\left(\mathrm{kg} / \mathrm{m}^{3}\right), \alpha_{i}(t)$ is hydration degree of the oxide compound $i^{\text {th }}$ at the age $t, t$ is the age of concrete (days).

According to some researchers, the hydration degree of each oxide compound depends on temperature, concrete mix proportion, and time. Details of the model of hydration degree can be found elsewhere $[30,31]$. The derived results of degree of hydration of cement in the tested concrete mixtures in this study are shown in Fig. 2a. The $\mathrm{W} / \mathrm{B}$ ratios were 0.4 and 0.6 in this study.

\subsubsection{Degree of pozzolanic reaction of fly ash}

While the degree of hydration can indicate the hydration process of OPC concrete, degree of pozzolanic reaction can represent the role of fly ash in cement-fly ash cementitious system. The degree of pozzolanic reaction is defined as the ratio of reacted fly ash to total fly ah in a mixture. The degree of pozzolanic reaction can be obtained by using Eq. (3).

$$
\alpha_{P o z}(t)=k_{P o z}(t) \times \alpha_{P o z}(365)
$$

where $k_{P o z}(t)$ is a ratio of fly ash reaction at the age $t$, $\alpha_{P o z}(365)$ is the degree of pozzolanic reaction at 1 year.

Similarly, the degree of pozzolanic reaction is a function of concrete mix proportion, temperature, time, and more importantly properties of the fly ash, such as replacement percentage, chemical compositions and fineness of fly ash. Details of the model can be found elsewhere $[30,31]$. The results of degree of pozzolanic reaction of fly ash in the tested concrete mixtures in this study, are illustrated in Fig. 2b.

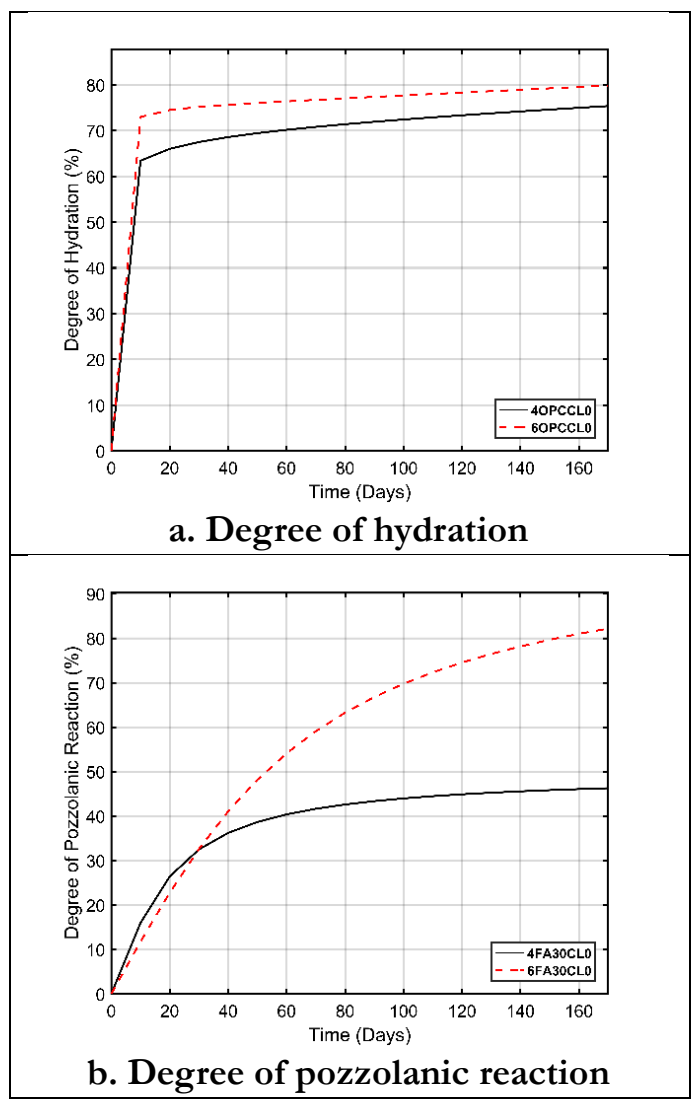

Fig. 2. Degree of hydration of cement and degree of pozzolanic reaction of fly ash in the author's tested concrete mixtures.

\subsection{Capillary Porosity}

Capillary porosity is a fraction of capillary pore volume per total volume of paste. The equation for estimating capillary porosity was adopted from Mindess et al. [13], as shown in Eq. (4). As can be seen, the capillary porosity is a function of water to binder ratio as well as hydration degree of cement. The capillary porosity of prepared specimens is shown in Fig. 3. The plot was made with the $\mathrm{W} / \mathrm{B}$ ratio 0.4 and 0.6 and the degree of hydration, computed by Eq. (2).

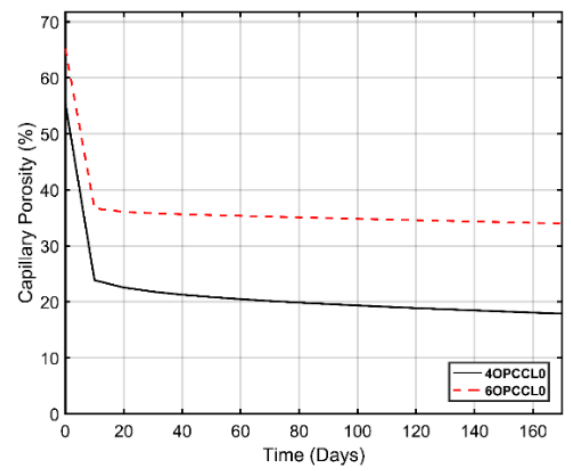

Fig. 3. Capillary porosity of concrete of author's prepared concrete specimens.

$$
P_{C a p}(t)=\frac{W / B-0.36 \times \alpha_{H y d}(t)}{W / B+0.32}
$$




\subsection{Electrical Resistivity of Concrete}

Generally, the process of hydration starts when unhydrated cement reacted with water to generate a structures of hydrated cement paste which include hydration products (such as calcium silicate hydrate - C$\mathrm{S}-\mathrm{H}$, calcium hydroxide - $\mathrm{CH}$, etc.) and pores structure (including gel pores and capillary pores). Hence, the porosity of concrete will be varied significantly during the hydration process, especially at the early age when the degree of hydration $\left(\alpha_{H y d}(t)\right)$ shows a very high rate (Fig. $2)$. It is worth mentioning that gel porosity was found relatively constant, approximately one-fourth of the total volume of the hydration product. The variation of the ratio of W/B mainly affects capillary porosity $\left(P_{\text {Cap }}(t)\right)$, as shown in Fig. 3. On the other hand, only the degree of hydration may not be able to represent the cementitious system containing cement and fly ash, because of the pozzolanic reaction at longer term. This is the reason that the model also took into account the degree of pozzolanic reaction $\left(\alpha_{P o z}(t)\right)$ for the case of fly ash concrete.

Lastly, the existence of chloride ions $\left(\beta_{C L}\right)$ in concrete was considered in the model of electrical resistivity. The presence of chloride in pore solution significantly increases the movement of charge ions in concrete. In other words, electrical resistivity decreases. The proposed equations for electrical resistivity are expressed from Eq. (5) to (8) for OPC and fly ash concrete.

For chloride-free OPC concrete:

$$
\begin{aligned}
r= & 207.18-184.88 \cdot W / B+30.74 \cdot e^{-0.018 \cdot \alpha_{H y d}(t)} \\
& +\frac{345.79}{P_{C a p}(t)}-298.9 \cdot e^{-17.62 \cdot \beta_{C L}}
\end{aligned}
$$

For chloride-free fly ash concrete:

$$
\begin{aligned}
r= & -187.52+258.3 \cdot W / B+9.7 \cdot e^{0.04 \% \% A} \\
& -1.2 \cdot \alpha_{H y d}(t)-\frac{624.22}{\alpha_{P o z}(t)}+\frac{822.59}{P_{C a p}(t)}+\frac{4.74}{\beta_{C L}}
\end{aligned}
$$

For chloride-contaminated OPC concrete:

$$
\begin{aligned}
r & =-32.7+\frac{11.15}{(W / B)^{0.34}}+0.25 \cdot \alpha_{H y d}(t) \\
& -\frac{21.32}{P_{C a p}(t)}+\frac{10.9}{\beta_{C L}^{0.31}}
\end{aligned}
$$

For chloride-contaminated fly ash concrete:

$$
\begin{array}{r}
r=34.85+0.04 \cdot W / B-0.35 \cdot \alpha_{H y d}(t) \\
-\frac{1347.37}{\alpha_{P o z}(t)}+\frac{441.63}{P_{C a p}(t)}+40.07 \cdot e^{-0.27 \cdot \beta_{C L}}
\end{array}
$$

In which:

$$
\beta_{C L}=\frac{\left(\left[C L^{-}\right]+0.1\right) \times W / B}{\frac{\% F A}{100}+1}
$$

where [CL-] is the content of chloride in concrete $\left(\mathrm{kg} / \mathrm{m}^{3}\right)$, $\mathrm{W} / \mathrm{B}$ is the water to binder ratio, $\% \mathrm{FA}$ is the percentage of fly ash replacement ( $\%$ by weight of total binder).

\subsection{Corrosion Potential of Reinforcing Steel}

Firstly, the degrees of hydration and pozzolanic reaction are attributed to transport of ions in concrete matrix through porosity. Therefore, the proposed model of corrosion potential takes the hydration reaction of cement and pozzolanic reaction of fly ash into account. It is also noted that the cement hydration process is dominant for the formation of microstructures of hydrated cement paste, not only the pores structure but also for the alkaline nature of concrete. Calcium hydroxide crystals or Portlandite plays a crucial role to provide a high alkaline condition in concrete, which contributes to the formation of passive film on surface of reinforcing steel $[13,14]$. It has been mentioned in various previous studies $[1-3,14,27,32]$ that this passive film protects the reinforcement in term of stabilizing potential on steel surface.

In the process of chloride-induced corrosion, when chloride ions reach the surface of steel, the passive film is gradually destroyed. As the passive film becomes weak, the reinforcement has high risk of corrosion $[1-3,14,27$, 32]. From that point of view, the following model concerns only the amount of chloride at the surface of steel only. The proposed model includes two separated equations, Eq. (10) to Eq. (12), for OPC and fly ash concrete.

For chloride-free OPC and fly ash concrete:

$$
\begin{aligned}
E_{\text {corr }}= & -0.5926-0.1437 \cdot \mathrm{W} / \mathrm{B}-6 \mathrm{E} \\
& -3 \cdot \% \mathrm{FA}-\frac{0.0958}{D}+7 \mathrm{E}-3 \cdot \alpha_{\mathrm{Hyd}}(t) \\
& -\frac{0.5576}{P_{C a p}(t)}+\frac{0.0029}{\beta_{C L}}
\end{aligned}
$$

For chloride-contaminated OPC concrete:

$$
\begin{aligned}
E_{\text {corr }}= & -5.2769-11.80 \cdot(W / B)^{0.3}+\frac{0.46}{D^{0.07}} \\
& +0.343 \cdot \alpha_{H y d}(t)+10.1 \cdot e^{0.0053 \cdot P_{C \text { CP }}(t)} \\
& +0.35 \cdot \beta_{C L}{ }^{0.3751}
\end{aligned}
$$

For chloride-contaminated fly ash concrete:

$$
\begin{aligned}
E_{\text {corr }}= & -0.43-\frac{0.41}{D^{0.10}}+\frac{4.22}{\alpha_{H y d}(t)}+\frac{0.9}{\alpha_{P o z}(t)} \\
& +0.37 \cdot e^{0.0037 \cdot P_{C \text { cop }}(t)}-0.12 \cdot \ln \left(\beta_{C L}\right)
\end{aligned}
$$

where $\mathrm{E}_{\text {corr }}$ is the corrosion potential of reinforcing steel (V vs. CSE), D is the concrete covering $(\mathrm{cm})$.

The fact that concrete has very high resistivity can lead to a phenomenon of ohmic drop, or IR drop. This phenomenon is more significant when the thickness of concrete increases because the measurement mostly made on surface of concrete. That is why the proposed model 
considered the influence of covering depth on the predicted potential.

\section{Results and Discussion}

The following sections show the experimental and predicted results of the electrical resistivity and corrosion potential obtained in this study. The effects of the hydration of cement, the pozzolanic reaction of fly ash, the presence of chloride ions and time of exposure on the electrical resistivity and corrosion potential are discussed. It is worth mentioning that the experimental results were obtained from direct measurements (Fig. 1), and they were used to develop the prediction models.

\subsection{Electrical Resistivity}

Figure 4 and Figure 5 show the experimental and predicted results of the electrical resistivity of concrete. As one of the concern parameters in this study, the electrical resistivity of concrete could be used to estimated level of reinforcement corrosion. In practice, when the value of electrical resistivity of concrete was computed from the proposed model, the corrosion level can be estimated. The estimation can be made based on the relationship between the electrical resistivity and corrosion rate, as shown in Table 3.

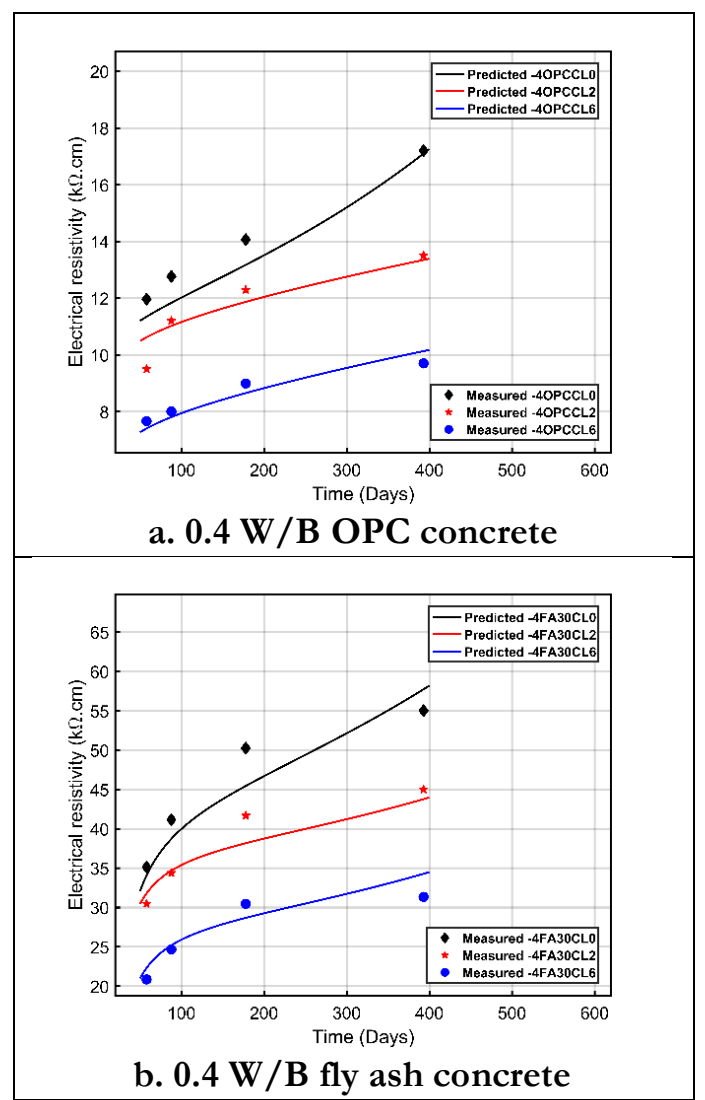

Fig. 4. Variation of the electrical resistivity of concrete with various chloride contents.

As shown in Fig. 4, the electrical resistivity of the chloride-free OPC concrete mixture with $\mathrm{W} / \mathrm{B}$ of 0.4 increased from $12 \mathrm{k} \Omega . \mathrm{cm}$ at the age of 1 year to approximately $17 \mathrm{k} \Omega . \mathrm{cm}$ (Fig. 4a). Similar results can be found for the case of fly ash concrete (Fig. 4b). This indicated that the electrical resistivity of concrete increased when the degree of hydration and pozzolanic reaction increased. As the hydration progressed, the pore structures of the cement concrete became smaller (Fig. 3), as a result the movement of charge ions became more difficult. The results reflected the findings of previous studies [1-3, 14, 16, 17, 26, 27, 32-38]. Additionally, not only the time-dependent reaction, but other parameters of concrete mix proportion can also change the electrical resistivity.

Table 3. Relationship between the level of reinforcement corrosion and electrical resistivity of concrete [3].

\begin{tabular}{|c|c|c|c|c|}
\hline Corrosion level & Low & Intermediate & High & $\begin{array}{l}\text { Very } \\
\text { high }\end{array}$ \\
\hline $\begin{array}{l}\text { Electrical } \\
\text { resistivity } \\
(\mathrm{k} \Omega \cdot \mathrm{cm})\end{array}$ & $>20$ & 10 to 20 & $\begin{array}{c}5 \text { to } \\
10\end{array}$ & $<5$ \\
\hline
\end{tabular}

As can be seen in Fig. 4, the electrical resistivity of chloride-free concrete was higher than that of the chloride-contaminated concrete, for both OPC and fly ash concrete. This could be because the presence of chloride ions eased the movement of ions in both OPC and fly ash concrete. Additionally, as the chloride content was increased, the electrical resistivity became lower. In other words, the existence of chloride ions can increase the level of corrosion of reinforcement. The results showed good agreement with many other researchers [3, 32, 39]. An increase in chloride ions adds electrolytes in the concrete pore solution, leading to a decrease in concrete resistivity [1]. Solid salts, specifically $\mathrm{NaCl}$, can absorb water to form aqueous electrolytes, which then offers high conductivity for corrosion to occur [39].

As mentioned, using low W/B concrete and fly ash concrete also offers a high electrical resistivity, by the fact that the concrete porosity is smaller in low W/B concrete compared to that of high $\mathrm{W} / \mathrm{B}$ concrete. A low porosity constrained the movement of charge ions, as a result, the low porosity concrete has a high corrosion resistance. Regarding fly ash concrete, the pozzolanic reaction provided a long-term development of the electrical resistivity. The total porosity decreased, which is proportional to percentage of replacement of fly ash in the concrete mixture [13-15, 40]. It should be noted that the total porosity had not yet been considered in the adopted model, as expressed in Eq. (4).

It is also worth mentioning that the mentioned relationship (Table 3) is usually applied for OPC concrete rather than fly ash concrete. Even though there was $6 \mathrm{~kg} / \mathrm{m}^{3}$ [CL] presented in the tested fly ash concrete, the electrical resistivity was still higher than $20 \mathrm{k} \Omega . \mathrm{cm}$. And based on the relationship in Table 3, a low level of corrosion would be claimed, which was quite questionable. From this point of view, a new relationship between the 
electrical resistivity and corrosion level should be developed in the future study, where the effect of the type of binder should be considered.

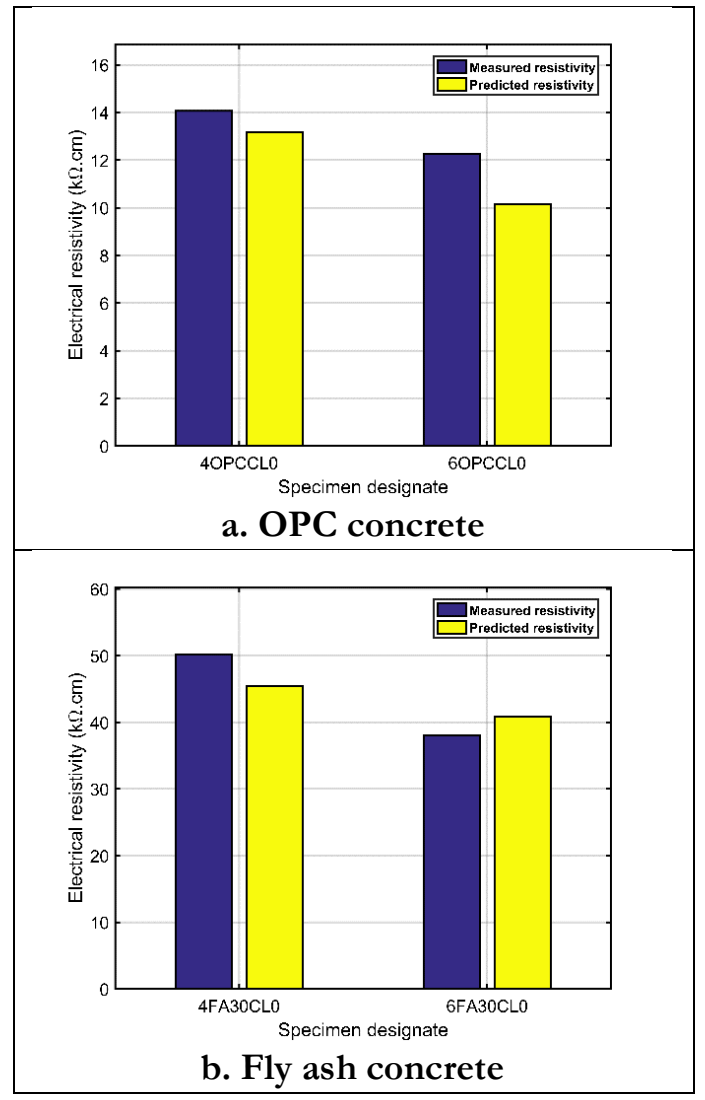

Fig. 5. Variation of the electrical resistivity of concrete with various concrete proportions.

\subsection{Corrosion Potential}

As the second concerned property of this study, the corrosion potential of steel could provide a sense of probability of corrosion and position where corrosion may take place. Based on the proposed model, corrosion potential can be computed. The obtained corrosion potential can be used to evaluate the corrosion possibility with their relationship being demonstrated in Table 4 .

Figure 6 illustrates the change with age of the corrosion potential of steel in the specimens with and without fly ash. An increase in the corrosion potential was found with time in both OPC and fly ash concrete when [CL-] was not incorporated in the concrete. Firstly, these results emphasized that the contribution of passive film since its formation is also not interrupted in chloride-free concrete. The passivity, therefore, can stabilize potential on the steel surface. Furthermore, the increased results of the corrosion potential were also contributed by the hydration reaction in OPC concrete and both hydration and pozzolanic reaction in the fly ash concrete. As the porosity of concrete decreases during the hydration, the movement of charge ions is constrained more significantly. Because of this restriction, the corrosion of reinforcement shows low possibility to occur, based on the above relationship (Table 4). However, it should be noted that the increase in the corrosion potential strongly depends on the concrete mix proportion as well as the content of chloride.

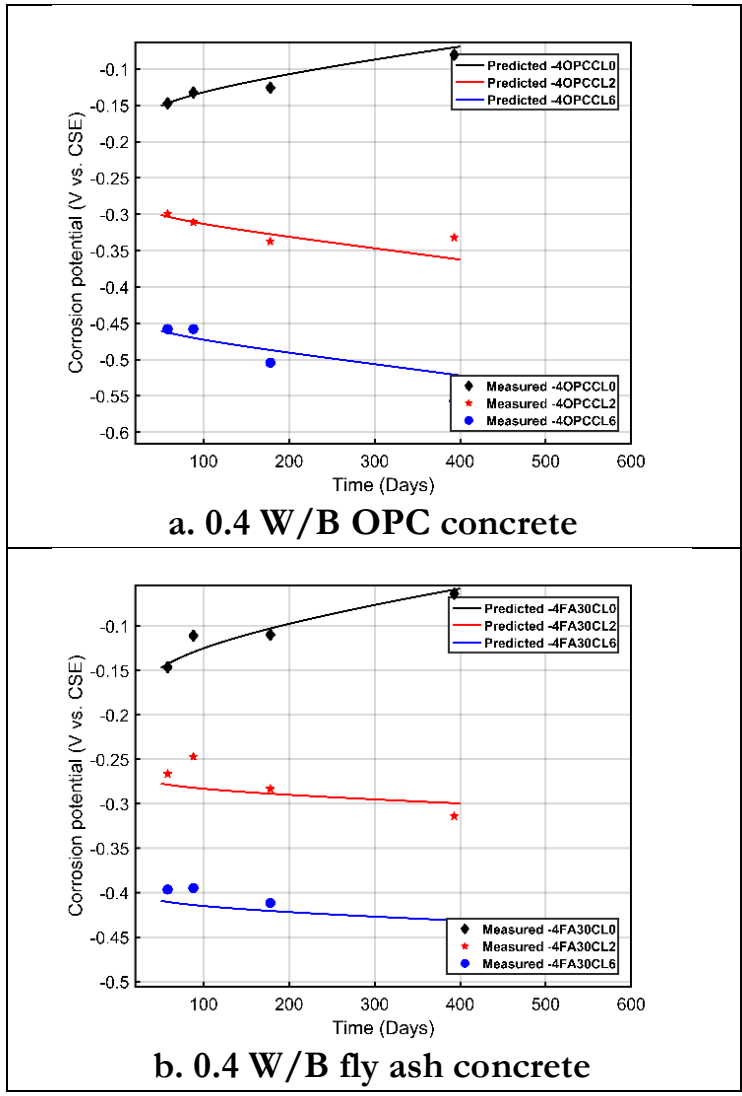

Fig. 6. Variation of corrosion potential of reinforcing steel with various chloride contents.

Table 4. Relationship between corrosion potential and probability of corrosion of reinforcement [29].

\begin{tabular}{|c|c|c|c|c|}
\hline $\begin{array}{l}\text { Corrosion } \\
\text { probability }\end{array}$ & Low & Intermediate & High & Severe \\
\hline Corrosion & & & 0.35 & \\
\hline $\begin{array}{l}\text { potential } \\
(- \text { V. CSE })\end{array}$ & $>0.2$ & 0.2 to 0.35 & $\begin{array}{c}\text { to } \\
0.5 \\
\end{array}$ & $<0.5$ \\
\hline
\end{tabular}

The presence of chloride ions significantly decreases the corrosion potential. For example, after 30 days of exposure, the corrosion potential of $0.4 \mathrm{~W} / \mathrm{B}$ OPC concrete with $2 \mathrm{~kg} / \mathrm{m}^{3}$ [CL-] $(-0.3 \mathrm{~V})$ was lower than that of the chloride-free concrete, $-0.15 \mathrm{~V}$, as shown in Fig. 6 a. The corrosion potential of chloride-contaminated concrete tended to be lower with time, as shown in Fig. 6. The existence of chloride ions increases the probability of reinforcement corrosion. Because chloride ions weaken the passive film, the stabilization of potential starts reducing. Additionally, the movement of electrons in chloride-contaminated concrete is easier. Those mentioned factors reflected the fact that chloride could accelerate the corrosion of reinforcement.

The adjustment of water to binder ratio and introduction of fly ash affect directly to the concrete porosity. Low W/B concrete possesses a low porosity, hence it provided a less negative corrosion potential. Fly 
ash could even offer a significant restriction of ions movement $[1-3,21,26,32]$. It is also worth mentioning that products of fly ash reaction can capture free chloride in pore solution. A decrease in free chloride concentration lowers the probability of corrosion of reinforcement [1-3, $23,26,33,35,36,38,41,42]$. It is also noted that the effects of type of binder, not only the fly ash but also other supplementary concrete admixtures such as silica fume, ground blast-furnace slag, etc., have not yet been taken into account in the corrosion probability evaluation in Table 4. On this standpoint, a new relationship of corrosion potential should be proposed in the future study.

\section{Model Verification}

The proposed models of both electrical resistivity and corrosion potential were verified by our experimental results and results obtained from other studies [5, 6, 1623], as shown in Fig. 7 and Fig. 8. Summary of experimental conditions of other studies are provided in Table 5 and Table 6. Figure $7 \mathrm{a}$ and Figure $8 \mathrm{a}$ demonstrate the verifications with the experimental results of this study. The experimental results of electrical resistivity and corrosion potential were obtained for both OPC and fly ash concrete specimens. As can be seen, an approximately $\pm 30 \%$ deviation was achieved for the model of electrical resistivity and corrosion potential. In the future, timedependent deterioration of concrete cover will be considered in the prediction models.

\section{Conclusions}

Based on the results presented above, the conclusions can be drawn as follows:

1. Electrical resistivity and corrosion potential are time-dependent. At long term, the microstructure of concrete became denser, representing by high degree of hydration and low porosity. This phenomenon decreased the movement of ions, which also means that corrosion resistance of concrete increased. In particular, high electrical resistivity was observed simultaneously with less negative corrosion potential.

2. The introduction of fly ash, and the increase of chloride content showed contradict effects on the corrosion durability of the tested specimens. The experimental results revealed that the cement-fly ash cementitious system provided high electrical resistivity, or high corrosion resistance. Meanwhile, the existence of chloride ions weakened the passive film and accelerated the flow of electrons in the system. Consequently, a low corrosion resistance and more importantly a high level of corrosion could be expected.

3. Finally, the proposed models for predicting the electrical resistivity and corrosion potential took into account the hydration and pozzolanic reactions of cement-fly ash cementitious materials. The verifications showed an accuracy of approximately $\pm 30 \%$ for the model of electrical resistivity and corrosion potential.

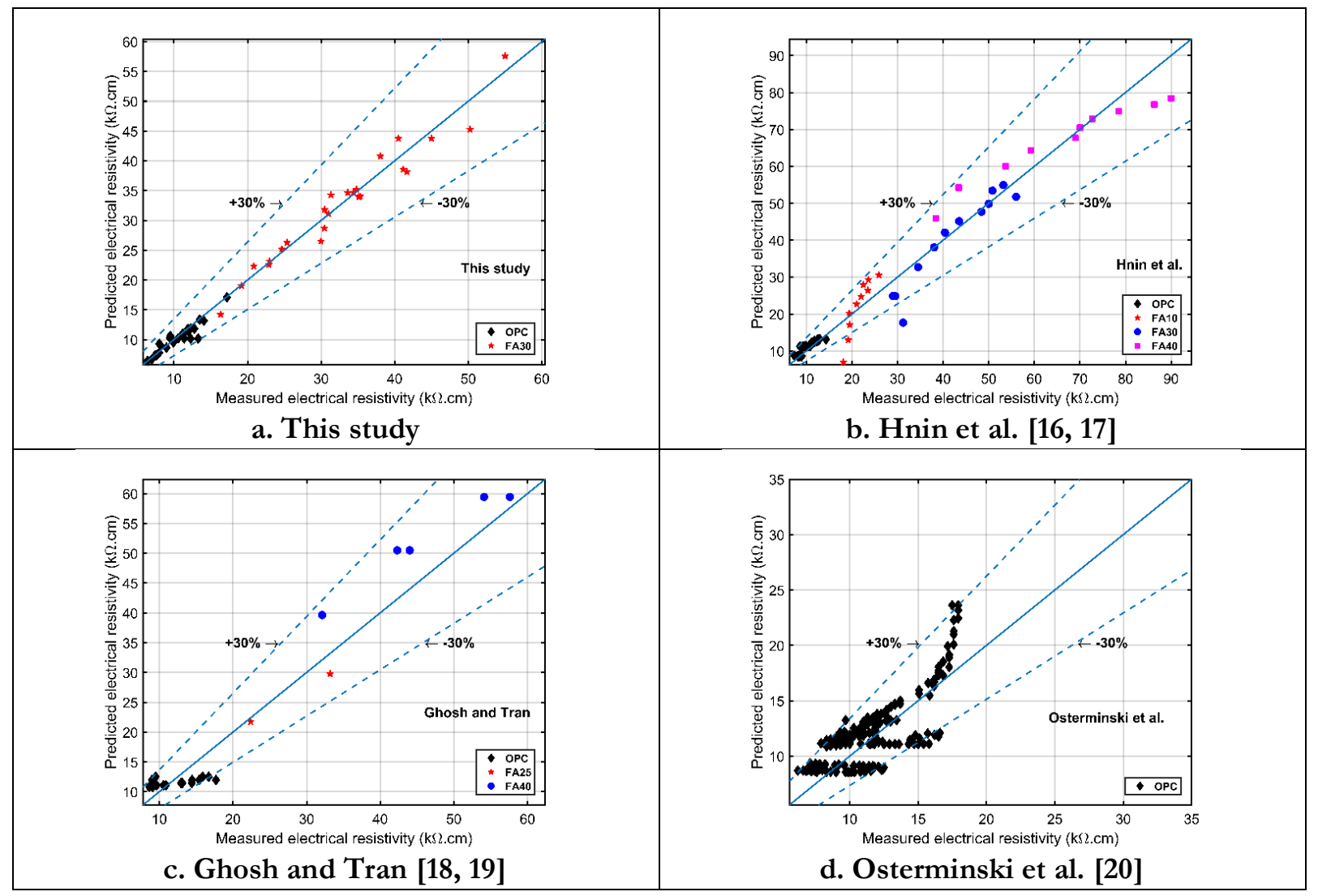

Fig. 7. Verification of electrical resistivity model with experimental data. 


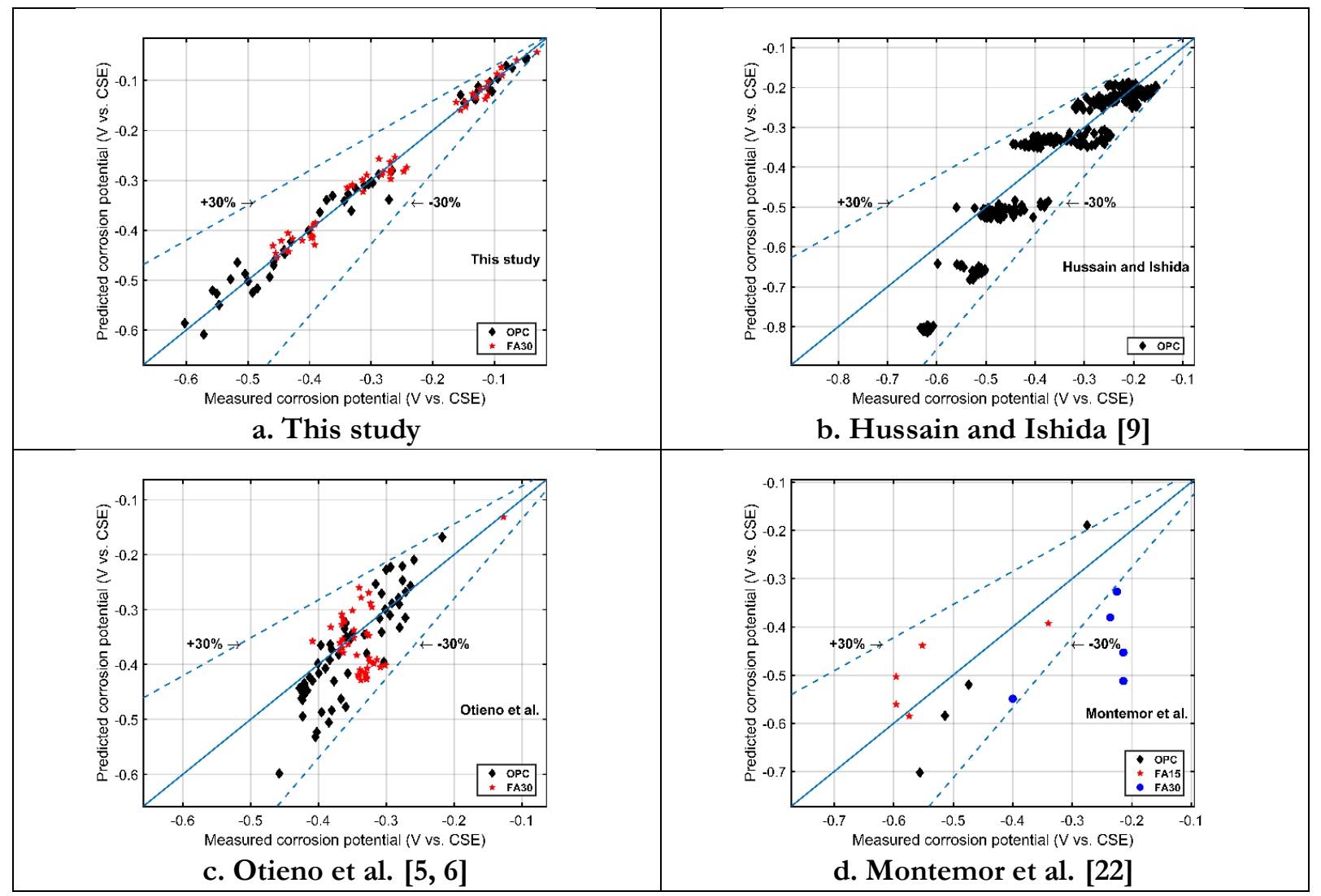

Fig. 8. Verification of corrosion potential with experimental data.

Table 5. Test conditions of previous studies used in the verification of the proposed model of electrical resistivity.

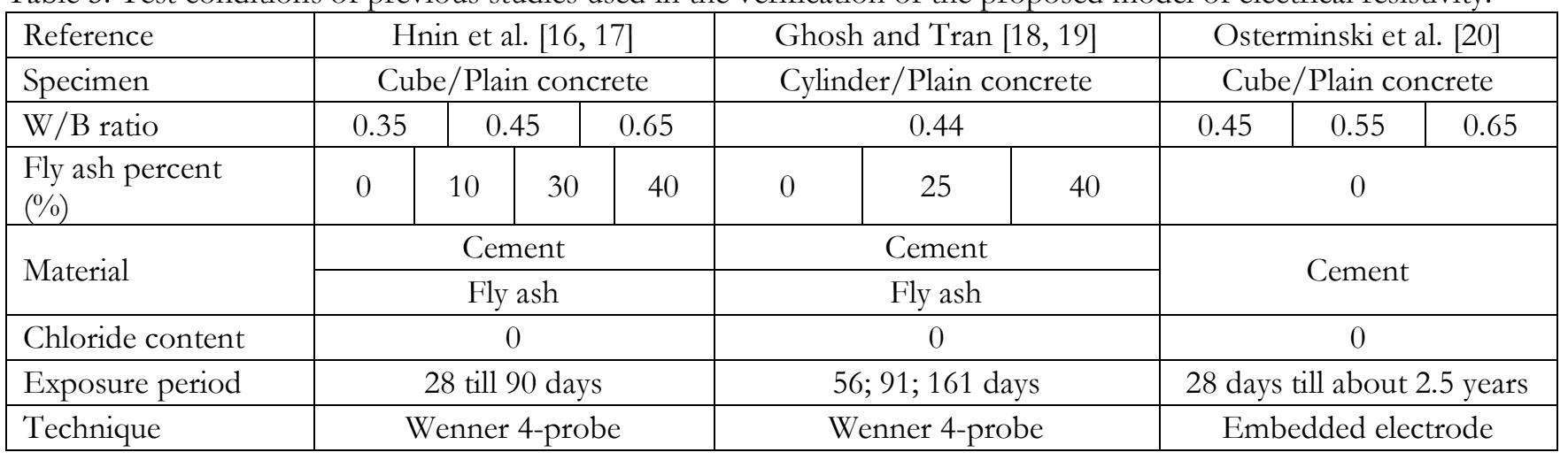

Table 6. Test conditions of previous studies used in the verification of the proposed model of corrosion potential.

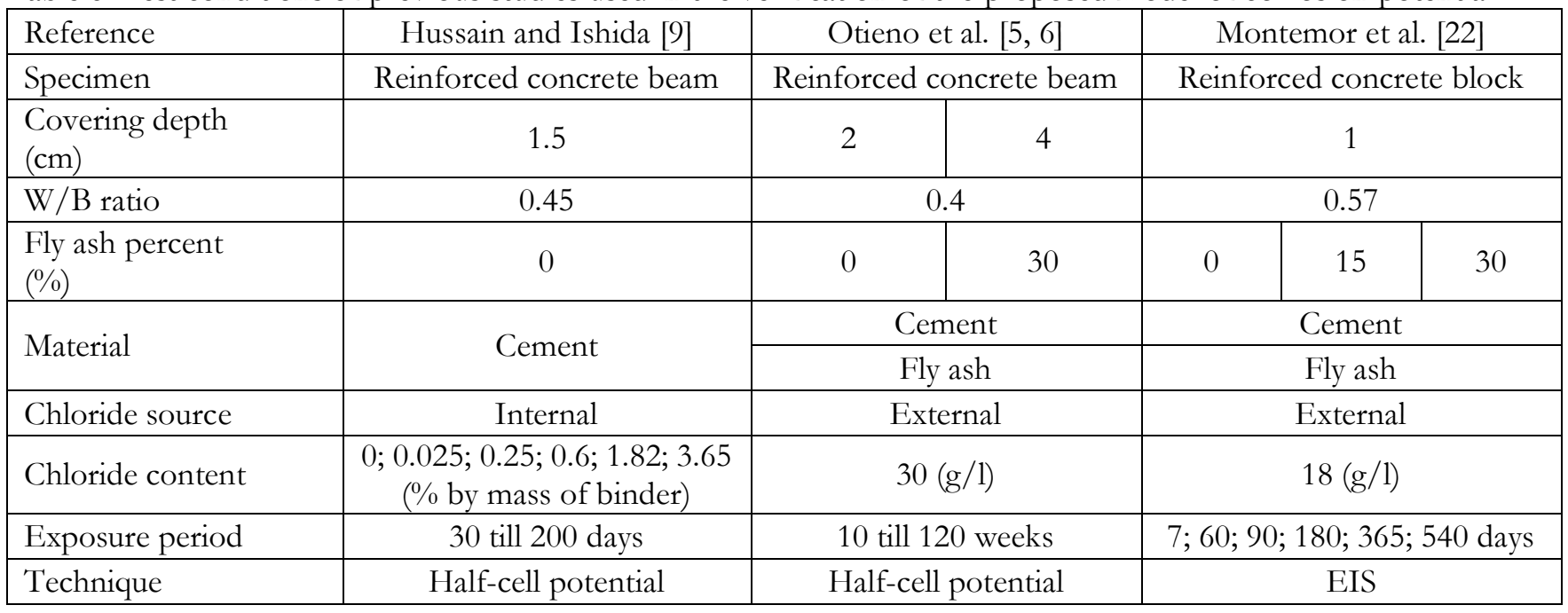




\section{Acknowledgements}

The author would like to acknowledge the National Metal and Materials Technology Centre and the Construction and Maintenance Technology Research Centre, Sirindhorn International Institute of Technology for supporting the equipment during the research. The author would like to express a great gratitude to Prof. Somnuk Tangtermsirikul and Dr. Pakawat Sancharoen for countless and helpful discussions throughout the research.

\section{References}

[1] A. Bentur, S. Diamond, and N. Berke, Steel Corrosion in Concrete: Fundamentals and Civil Engineering Practice. London: E \& FN Spon, 1997.

[2] L. Bertolini, B. Elsener, P. Pedeferri, and R. Polder, Corrosion of Steel in Concrete: Prevention, Diagnosis, Repair. Weinheim: John Wiley \& Sons, 2004.

[3] J. P. Broomfield, Corrosion of Steel in Concrete: Understanding, Investigation and Repair. London, UK: E \& FN Spon, 1997.

[4] M. Otieno, H. Beushausen, and M. Alexander, "Chloride-induced corrosion of steel in cracked concrete-Part II: Corrosion rate prediction models," Cement and Concrete Research, vol. 79, pp. 386-394, 2016

[5] M. Otieno, H.-D. Beushausen, and M. Alexander, "Chloride-induce corrosion of steel in cracked cocnrete - Part I: Experimental studies under accelerated and natural marine enivironments," Cement and Concrete Research, vol. 79, pp. 373-385, 2016

[6] A. Michel, M. Otieno, H. Stang, and M. R. Geiker, "Propagation of steel corrosion in concrete: Experimental and numerical investigations," Cement and Concrete Composites, vol. 70, pp. 171-182, 2016.

[7] B. Yu, L. Yang, M. Wu, and B. Li, "Practical model for predicting corrosion rate of steel reinforcement in concrete structures," Construction and Building Materials, vol. 54, pp. 385-401, 2014.

[8] B. Yu, J. Liu, and Z. Chen, "Probabilistic evaluation method for corrosion risk of steel reinforcement based on concrete resistivity," Construction and Building Materials, vol. 138, pp. 101-113, 2017.

[9] R. R. Hussain and T. Ishida, "Enhanced electrochemical corrosion model for reinforced concrete under severe coupled action of chloride and temperature," Construction and Building Materials, vol. 25, pp. 1305-1315, 2011.

[10] K. Osterminski, P. Schieß1, A. Volkwein, and T. F. Mayer, "Modelling reinforcement corrosion usability of a factorial approach for modelling resistivity of concrete," Materials and Corrosion, vol. 57, 2006.

[11] C. Alonso, C. Andrade, and J. A. Gonzales, "Relation between resistivity and corrosion rate of reinforcements in carbonated mortar made with several cement types," Cement and Concrete Research, vol. 8, pp. 687-698, 1988.
[12] P. Ghods, O. B. Isgor, and M. Pour-Ghaz, "Experimental verification and application of a practical corrosion model for uniformly depassivated steel in concrete," Material and Structures, vol. 41, pp. 1211-1223, 2008.

[13] S. Mindess, J. F. Young, and D. Darwin, Concrete, 2nd ed. New Jersey, US: Prentice-Hall, 1981.

[14] P. K. M. Mehta and Paulo J. M., Concrete: Microstructure, Properties, and Materials, 3rd ed. McGraw-Hill, 2006.

[15] A. M. Neville, Properties of concrete, 4th ed. England: Pearson Education Limited, 2002.

[16] S. W. Hnin, P. Sancharoen, and S. Tangtermsirikul, "Effects of concrete mix proportion on electrical resistivity of concrete," Materials Science Forum, vol. 866, pp. 68-72, 2016.

[17] S. W. Hnin, P. Sancharoen, and S. Tangtermsirikul, "Effects of mix proportion on electrical resistivity of concrete with fly ash," ASEAN Engineering Journal,, vol. 7, pp. 53-65, 2017.

[18] P. Ghosh and Q. Tran, "Correlation between bulk and surface resistivity of concrete," International Journal of Concrete Structures and Materials, pp. 119-132, 2015.

[19] P. Ghosh and Q. Tran, "Influence of parameters on surface resistivity of concrete," Cement \& Concrete Composites, vol. 62, pp. 134-145, 2015.

[20] K. Osterminski, R. B. Polder, and P. Schießl, "Long term behaviour of the resistivity of concrete," HERON, vol. 57, no. 3, pp. 211-230, 2012.

[21] R. R. Hussain, M. Wasim, and T. Ishida, "Induced macro-cell corrosion phenomenon in the simulated repaired reinforced concrete patch," Australian Journal of Civil Engineering, vol. 8, pp. 53-60, 2010.

[22] M. F. Montemor, A. M. P. Simões, and M. M. Salta, "Effect of fly ash on concrete reinforcement corrosion studied by EIS," Cement \& Concrete Composites, vol. 22, pp. 175-185, 2000.

[23] D. V. P. Tran, P. Sancharoen, P. Klomjit, and S. Tangtermsirikul, "Factors affecting half-cell potential profile of patching repaired concrete," in $3 r d A C F$ Symposium 2019, Sapporo, Japan, 2019.

[24] Standard Specification for Portland Cement, ASTM C 150, 2007.

[25] Coal Fly Ash for Use as An Admixture in Concrete, TIS 2135-2545, 2003.

[26] D. V. P. Tran, P. Sancharoen, P. Klomjit, and S. Tangtermsirikul, "Electrochemical compatibility of patching repaired reinforced concrete: Experimental and numerical approach," Journal of Adhesion Science and Technology, vol. 34, no. 8, pp. 828-848, 2019.

[27] V. M. Malhotra and N. J. Carino, Handbook on Nondestructive Testing of Concrete, 2nd ed. Florida: CRC Press LLC, 2004.

[28] R. P. W. Vassie, "Evaluation of techniques for investigating the corrosion of steel in concrete," in TRRL Supplementary Report 39. London: Transport and Road Research Laboratory, 1978.

[29] Standard Test Method for Corrosion Potentials of Uncoated Reinforcing Steel in Concrete, ASTM C 876, 2015. 
[30] S. Tangtermsirikul and W. Saengsoy, "Simulation of free water content of paste with fly ash," Research and Development Journal, vol. 13, pp. 1-10, 2002.

[31] N. Nipatsat and S. Tangtermsirikul, "Compressive strength prediction model for fly ash concrete," Thammasat International Journal of Science and Technology, vol. 11, pp. 1-7, 2000.

[32] M. G. Richardson, Fundamentals of Durable Reinforced Concrete. London: Spon Press, 2002.

[33] M. V. Tran and D. V. P. Tran, "Effect of temperature and humidity cycling on reinforcement corrosion," in 11th SEATUC Symposium, Viet Nam, 2017.

[34] V. Saraswathy, S. Muralidharan, K. Thangavel, and S. Srinivasan, "Influence of activated fly ash on corrosion-resistance and strength of concrete," Cement \& Concrete Composites, vol. 25, pp. 673-680, 2003.

[35] M. V. Tran, D. V. P. Tran, and M. M. A. B. Abdullah, "Effect of interrupting electricity period on electrochemical chloride extraction of reinforced concrete," Applied Mechanics and Materials, vol. 754755, pp. 342-347, 2015.

[36] M. V. Tran and D. V. P. Tran, "Effect of thermalhumid media on durability of CFRP-wrapped reinforced concrete columns," presented at the CIGOS 2017, Ho Chi Minh City, Viet Nam, 2017.
[37] D. V. P. Tran, P. Sancharoen, P. Klomjit, and S. Tangtermsirikul, "Effects of concrete mix proportion and chloride content on electrochemical properties of reinforcing steel in concrete," Engineering Journal, vol. 24, no. 3, pp. 23-34, 2020.

[38] D. V. P. Tran, P. Sancharoen, P. Klomjit, and S. Tangtermsirikul, "Electrical resistivity and corrosion potential of reinforced concrete: Influencing factors and prediction models," Journal of Adhesion Science and Technology, vol. 34, no. 19, pp. 2107-2119, 2020.

[39] E. Schindelholz, B. E. Risteen, and R. G. Kelly, "Effect of relative humidity on corrosion of steel under sea salt aerosol proxies - I NaCl," Journal of The Electrochemical Society, vol. 161, no. 10, pp. 450-459, 2014.

[40] P. Chindaprasirt, C. Jaturapitakkul, and T. Sinsirib, "Effect of fly ash fineness on compressive strength and pore size of blended cement paste," Cement and Concrete Composites, vol. 27, no. 4, pp. 425-428, 2005.

[41] K. Y. Ann and H.-W. Song, "Chloride threshold level for corrosion of steel in concrete," Corrosion Science, vol. 49, pp. 4113-4133, 2007.

[42] P. Bamforth and W. Price, "Factors influencing chloride ingress into marine structures," Infrastructure, Research, New Applications, vol. 2, pp. 1105-18, 1993.

Dong Viet Phuong Tran, photograph and biography not available at the time of publication. 